\title{
Optimization of Cut-off Grades for Molybdenum and Tungsten Open-pit Mines
}

\author{
Qinghua $\mathrm{Gu}^{1 *}$, Jin Yuan ${ }^{2}$, Yichuan $\mathrm{Lv}^{2}$, Qiong $\mathrm{Wu}^{1}$ and Caiwu $\mathrm{Lu}^{1}$ \\ ${ }^{1}$ Xi' an University of Architecture \& Technology, Xi'an, Shaanxi, China \\ ${ }^{2}$ China National Petroleum Corporation Shaanxi Sales Company, Xi'an, Shaanxi, China
}

\begin{abstract}
The cut-off grade is one of the important parameters of mining production. Different material cut-off grade is directed to different destinations. Based on reasonable and optimal cut-off grade, long term mining plan and investment decision analysis can be made for mining managers. In view of multiple-metals open-pit, the paper has proposed that multiple-metals cut-off grade optimization model is set using the objective function to maximize net present value (NPV). The method of equivalent coefficient calculation is proposed to convert multi-metals cut-off grade optimization to a single metal cut-off grade optimization. Then the optimization model is applied in a molybdenum and tungsten large open-pit mine in china. The parameters of concentrate price are calculated by PRT in the model and the curve of grade-recovery rate is analyzed and studied according to actual production data. Based on 3D metal deposit model, the distribution of gradetonnage is analyzed. At final step, an optimal cut-off grade is proposed to guarantee to maximize NPV. The example shows that the model of multiple-metals cut-off grade optimization can provide reasonable analysis for optimal multi-metals cut-off grade and develop optimal production strategies.
\end{abstract}

Keywords: equivalent grade, multiple metal, cut-off grade, NPV, optimization

\section{Introduction}

Cut-off grade is one of the most important parameters in metal ore mining because of its influence on the overall economic profit of mining production. Along with the development of the mining production, dynamic optimization of cut-off grade is necessary through the analysis of technical economy. It is better to manage the mining production according to the variation of market. The cut-off grade plays an important role in mining production.

Cut-off grade is defined (Taylor 1985) that it is used to discriminate ore and rock. From the perspective of economics, it is a grade value which makes profit and cost equal in mining. When useful components grade in mining ore is higher than or equal the cut-off grade, it should be as ore; otherwise, it should be divided into waste rock. The optimization theory of single metal cut-off grade has been put forward (Lane 1988) earliest, which is considered to be a landmark in cut-off grade optimization. Opportunity costs had been proposed (Whittle and Wharton 1995), which includes two virtual costs, namely the delay cost and change cost. But this algorithm is not available for multi-metals mine. It is proposed (Annels 1991) that the multi-metals valuation can be evaluated by net metal amount one ton ore (NSR). In this case, one metal grade can be converted into a different kind of metal grade. It is proposed (Osanloo 2003) that equivalent grade factors are used to find the optimum cut-off grades of multiple metal deposits. A net present value maximization model has been set up (Asad 2011) for optimum cut-off grade of open pit mining operations considering the impact of stockpile. It is proposed ( $\mathrm{Li} 2010)$ that profit method is adopted to calculate the equivalent copper grade of associated molybdenum in a copper and molybdenum mine. An underground metal cut-off grade optimization method is proposed (Gu et al 2010 and 2013) from the perspective of ore spatial distribution. A dynamic optimization model of cut-off grade in an open pit has been established (Xie et al 2003) through marginal analysis method combined with time cost of capital and analysis of opportunity cost. A few researchers usually use the approach of break-even analysis to calculate cut-off grade and distinguish the ore block section. But this method is mostly not optimal. So net present value(NPV) is typically acknowledged to a more reasonable method of cut-off grade. The time cost of capital is fully considered in mining process. Maximum net present value for cut-off grade optimization has been widely recognized (Dagdelen 1993). However, each multi-metal deposit has its own feature with different production process and constraints. The cut-off grade optimization model has also been different (Cetin and Down 2002). In this paper, the equivalent grade and net present value is adapted to establish cut-off grade optimization, especially considering dynamic recovery rate. Taking a large molybdenum and tungsten open pit as an example, the optimal equivalent cut-off grade of molybdenum and tungsten is figured out under the current market environment. This can provide production criterion for multi-metals open pit.

\section{Multi-metals Cut-off Grade Optimization Model}

Maximum net present value is used to establish multi-metals cut-off grade optimization model based on the whole life

* Corresponding Author: Q.H. Gu, qinghuagu@126.com, phone: +86 13109546200

Copyright @ 2017 Canamaple Academia Services, http://press.camdemia.ca

DOI: $10.15273 /$ gree.2017.02.004 
time operations of mining stage-treatment stage-refining stage. But in china the refining stage of mining group is usually independent. The concentrate is usually the final product for sale in most enterprises. So this paper is mainly focus on the first two stages: mining and treatment. The cut-off grade optimization model is set up involving two phases:

(1) Mining stage: all kinds of ore are mined up to mining production capacity; (2) Treatment stage: ore is grinded and concentrated again up to processing capacity. In the above two stages, there are respectively production cost and production capacity constraints. So considering its own cost and sale income fully and multi-metals deposit contains two kinds of main useful elements, the overall profits are as follows:

$$
\begin{aligned}
& \operatorname{MaxNPV}=\sum_{n=1}^{N} \frac{P_{n}}{(1+d)^{n}} \\
& P_{n}=s_{1 n} Q_{1 n}+s_{2 n} Q_{2 n}-m_{n} Q_{m_{n}}- \\
& \quad\left(C_{1 n}+C_{2 n}\right) Q_{c n}-f_{n}-w_{n} Q_{w n}
\end{aligned}
$$

Where $n=$ period (year) indicator, $N=$ total life operation (years), $P=$ profit $(\$ /$ year), $d=$ discount rate $(\%), m=$ mining $\operatorname{cost}\left(\$ /\right.$ ton), $\quad w=$ stripping cost $(\$ /$ ton $), \quad C_{l}=$ milling or concentrating cost of metal 1 (\$/ton), $C_{2}=$ milling or concentrating cost of metal 1 ( $\$ /$ ton), $f=$ fixed cost ( $\$ /$ year), $s_{1}=$ metal 1 concentrate selling price (\$/ton), $s_{2}=$ metal 2 concentrate selling price (\$/ton), $Q_{m}=$ quantity of ore mined (tons/year), $Q_{c}=$ quantity of ore processed (tons/year), $Q_{w}=$ quantity of rock mined (tons/year), $Q_{l}=$ quantity of metal 1 concentrated (tons/year), $Q_{2}=$ quantity of metal 2 concentrated (tons/year).

There are relationships between the quantities of metal 1 concentrated $Q_{1}$ and metal $2 Q_{2}$ and the quantities of ore processed $Q_{c}$ as follows:

$$
\begin{aligned}
& Q_{1} G_{1}=\bar{g}_{1} y_{1} Q_{c} \\
& Q_{2} G_{2}=\bar{g}_{2} y_{2} Q_{c}
\end{aligned}
$$

Where $\bar{g}_{1}$ is the average grade of ore processed containing metal $1, \bar{g}_{2}$ is the average grade of ore processed containing metal $2, y_{1}$ is the recovery rate of metal 1 from the ore, $y_{2}$ is the recovery rate of metal 2 from the ore, $G_{l}$ is the grade of metal 1 concentration, $G_{2}$ is the grade of metal 2 concentration.

Substituting Eq.(3) and Eq.(4) into Eq.(2) yields

$$
\begin{aligned}
P= & {\left[s_{1} \bar{g}_{1} y_{1} / G_{1}+s_{2} \bar{g}_{2} y_{2} / G_{2}-\left(C_{1}+C_{2}\right)\right] Q_{c} } \\
& -m Q_{m}-f-w Q_{w}
\end{aligned}
$$

In Eq.(5), $P$ is a grade function of metal 1 and metal 2. The grade of metal 2 is converting to grade of metal 1 by using equivalent factor. Equivalent factor is equal to

$$
F_{e q}=\frac{s_{2} y_{2} G_{1}}{s_{1} y_{1} G_{2}}
$$

Substituting Eq.(6) into Eq.(5) yields

$$
\begin{aligned}
P & =\left[\frac{s_{1}}{G_{1}} y_{1}\left(\bar{g}_{1}+\frac{s_{2} y_{2} G_{1}}{s_{1} y_{1} G_{2}} \bar{g}_{2}\right)-\left(C_{1}+C_{2}\right)\right] Q_{c} \\
& -m Q_{m}-f-w Q_{w}
\end{aligned}
$$

The average equivalent grade of multi-metals ore can be calculated based on equivalent factor and average grade of each metal as follows:

$$
\bar{g}_{e q}=\bar{g}_{1}+F_{e q} \bar{g}_{2}
$$

Substituting Eq.(8) into Eq.(7) yields

$$
P=\left[\frac{S_{1}}{G_{1}} y_{1} \bar{g}_{e q}-\left(C_{1}+C_{2}\right)\right] Q_{c}-m Q_{m}-f-w Q_{w}
$$

Maximizing the net present value for mining enterprises is necessary. Namely the sum of profits each year should be maximum. The earlier profit can be made, the less the net present value lost. Then more profits can be gained. Eq.(1) is the objective function for calculation of optimal cut-off grade of ore. The time $\mathrm{N}$ is related to the constraint production capacity. Two cases arise depending upon which of the two capacities is actually limiting factor.

Case 1: if the mining capacity $M$ is the main limiting factor, then the time $\mathrm{N}$ is given by

$$
N=\frac{Q_{m}}{M}
$$

Case 2: if the concentrating capacity $\mathrm{C}$ is the main limiting factor, then the time $\mathrm{N}$ is controlled by the concentrator.

$$
N=\frac{Q_{c}}{C}
$$

The final objective function of maximizing net present value is as follows:

$$
\begin{aligned}
\operatorname{Max} N P V & =\sum_{n=1}^{N} \frac{\left[\frac{S_{1 n}}{G_{n 1}} y_{1 n} \bar{g}_{\text {eqn }}-\left(C_{1 n}+C_{2 n}\right)\right] Q_{c n}}{(1+d)^{n}} \\
& -\sum_{n=1}^{N} \frac{m_{n} Q_{m n}-f_{n}-w Q_{w n}}{(1+d)^{n}}
\end{aligned}
$$

The equivalent factor is usually used to convert one metal grade to another metal grade in multi-metals deposits. Then the cut-off grade optimization model is converted into a single metal cut-off grade optimization. Based on Lane algorithm, the objective function is a unimodal function with above two constraint conditions. The maximum peak value can be found by iterative search method. However, due to the difference of the distribution to grade-ton for each deposit and the relationship of grade-recovery for each metal, it is very hard to calculate optimal grade. So the optimal grade is usually obtained by gradual approximation with different net present value scenarios.

\section{Example}

\subsection{Molybdenum tungsten deposit}

A large molybdenum and tungsten deposit locates in Henan province, China. The shape of largest ore body actually is simple. It is a thick and bedded ore body. There also are small ore bodies in the bottom and top of the main ore body. Molybdenum and tungsten are mainly metal elements associated with few Iron and Sulfur. With scope of the current mining license, the average grade of molybdenum is $0.10 \%$ and the associated tungsten is $0.07 \%$. According to mining conditions, the mining approach of open pit is available. So shovels and trucks are adopted to mining ores. 
Milling and flotation process is used to obtain molybdenum concentrate and tungsten concentrate.

So far the mining production capacity and mineral treatment capacity is 9.9 million tons per year. It has been mined for many years. But tungsten did not recycle in the early production. So after tungsten recycled, the optimal grade of two metals needs to be calculated. This paper is mainly focus on how to optimize the grade of molybdenum and tungsten based on above cut-off grade optimization model.

\subsection{Molybdenum and Tungsten 3D block model}

Based on geological resource reserve report and supplementary drilling exploration in recent years, a total of 142 geological drilling data are normalized and geological database is set up. Using mining software Surpac as platform, the 3D entity model of molybdenum and tungsten are constructed according to geological database and geological profile morphology. Figure 1 shows this model. Molybdenum ore body is larger than tungsten ore body. Tungsten is mainly located in skarn and calcium silicate hornfels. In the middle of ore body, the shapes and distribution of molybdenum and tungsten ore body in the skarn are similar. Large difference appears in the edge of ore body. Tungsten ore body typically locates at bottom of molybdenum ore body. In the horizontal direction, the tungsten grade in the south is higher than in the north; the tungsten grade in the west is higher than in the east; in the vertical direction, the grade is higher in the bottom.

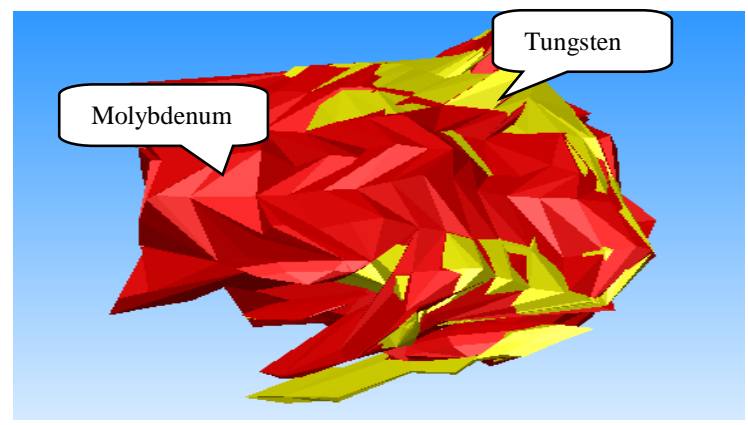

Figure 1. 3D model of molybdenum and tungsten.

Based on above molybdenum and tungsten 3D model, the raw data of geological drilling is analysed by statistic method. Some grade values are too high to evaluate. All raw data is processed and grouped. All the sample data normally belong to normal distribution. A total of molybdenum sample 14950 groups are effective and a total of tungsten sample 8483 groups. With the variation functions, Kriging method is used to evaluate the grade of each block model, as shown in Figure 2.

\subsection{The equivalent grade of multi-metals}

(1) Production price

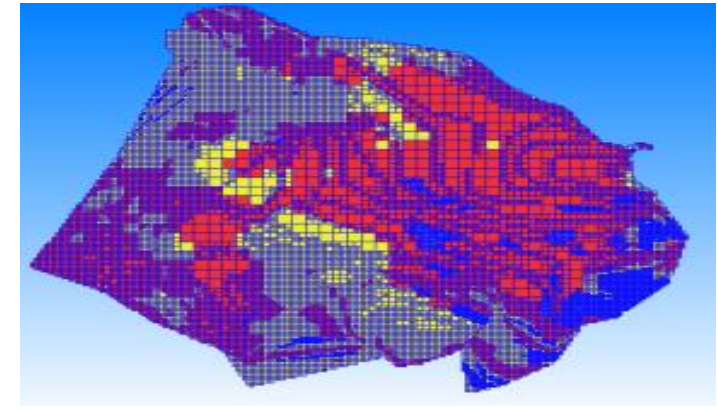

(a) Molybdenum

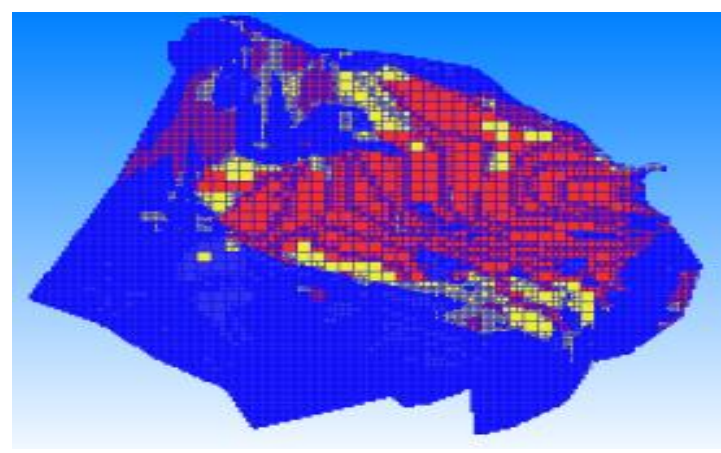

(b) Tungsten

Figure 2. The grade distribution of molybdenum and tungsten block model.

With the price changing trend of molybdenum and tungsten concentrate in recent years and volatility of market price, some statistical analysis is done for the prices data of molybdenum and tungsten concentrate. The maximum, most likely value and minimum of two kinds of concentrate can be obtained. Then the future prices of molybdenum and tungsten concentrates will be calculated through Program Evaluation and Review Technique(PERT) as follows ( $\mathrm{Li}$ and $\mathrm{Lu} 2012$ ):

The price of molybdenum concentrate per unit is:

$$
\begin{aligned}
P_{l}= & \frac{\text { Max }+4 * \text { Mostlikely }+ \text { Min }}{6} \\
& =(460.5+4 * 275.9+212.9) / 6=296.17 \$ / \text { ton }
\end{aligned}
$$

The price of tungsten concentrate per unit is:

$$
\begin{aligned}
P_{2} & =\frac{\text { Max }+4 * \text { Mostlikely }+ \text { Min }}{6} \\
& =(413.4+4 * 270.2+150.5) / 6=274.12 \$ / \text { ton }
\end{aligned}
$$

(2) The recovery of molybdenum and tungsten

The actual raw data of metal grade and recovery rate are collected respectively from molybdenum and tungsten processing plant, which belong to Luoyang Luanchuan Molybdenum Industry Group nc. 1120 groups of molybdenum grade and recovery rate and 1636 groups of tungsten grade and recovery rate are acquired. Then all data is analysed and processed as samples. After doing some statistical analysis, it seems that the ratio between molybdenum recovery rate and tungsten recovery rate is mostly constant. Details is shown in $[8,15]$, namely

$$
\xi=\frac{y_{2}}{y_{1}}=0.9579
$$


Through the statistical analysis of molybdenum and tungsten grade-recovery, it is shown that when the metal grades become higher and higher, the corresponding recovery rates will increase gradually. However, due to some blocking conditions on the growth rate of recovery rate, such as production process, natural resources and environment, the blocking effects are more and more with the increase of the grade. So the Logistic model is adopted to set up the curve relationship of molybdenum grade-recovery rate. The least square method is used to the fitting data of Logistic model. It makes points locate at two side of curve as many as possible. MATLAB is used to nonlinear data fitting for many times and finally parameters $x_{m}$ and $r$ is obtained with value $86.5095,44.8110$. Tungsten grade will convert into equivalent molybdenum grade. So the relationship curve model of molybdenum grade-recovery is obtained as follows:

$$
\mathrm{y}=\frac{86.5095}{1+\left(\frac{86.5095}{64}-1\right) e^{-44.8810(t-0.062)}}
$$

The curve of molybdenum grade-recovery rate is shown in Matlab as follows:

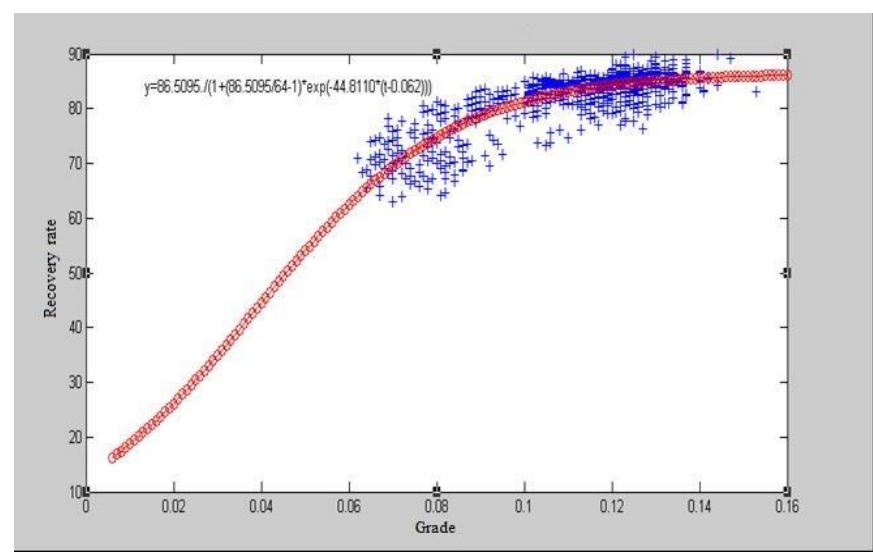

Figure 3. The fitting curve of molybdenum grade-recovery rate.

(3) Equivalent factor and equivalent grade

After milling and processing, the grade of molybdenum concentrate typically is $47 \%$ and the grade of tungsten concentrate is $30 \%$. Substituting those parameters into Eq.(6) and Eq.(8), the equivalent factor for converting tungsten grade into molybdenum grade can be calculated as follows:

$$
\begin{aligned}
& F_{e q}=\frac{s_{2} y_{2} G_{1}}{s_{1} y_{1} G_{2}}=\frac{1699.3 \times 30 \times 0.47}{2036.5 \times 47 \times 0.30} \times 0.9579=0.79 \\
& g_{e q}=g_{m o 3}+0.79 * g_{w o 3}
\end{aligned}
$$

Using the above equivalent factor, all the tungsten grades are converted into molybdenum grades in the samples. The equivalent grades in all blocks are calculated and evaluated again. The block model of equivalent molybdenum grade is shown in Figure 4.

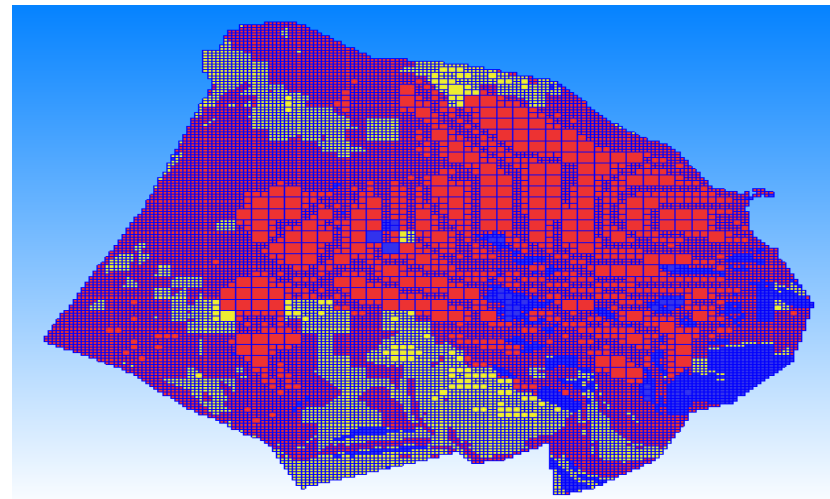

Figure 4. Distribution of equivalent molybdenum grade in block model.

\subsection{Parameters of equivalent cut-off grade optimization}

The main input parameters in the model of equivalent cut-off grade optimization are shown in Table 1 . The costs, prices, capacities, quantities and recoveries are demonstrated. After converting, the equivalent molybdenum grades are normally larger than before. The corresponding recovery rate can be calculated by Logistic model. This is second time to optimize open pit production. So the total investment is 229.1274 million dollars, including new construction investment is 99.6371 million dollars and the present value of fixed assets 43.2806 million dollars, the flow capital 86.2097 million dollars. The time for ream stripping is 1year.

Table 1. Economic parameters for optimization example.

\begin{tabular}{ccc}
\hline Parameter & Unit & Quantity \\
\hline $\begin{array}{c}\text { Molybdenum } \\
\text { concentrate }\end{array}$ & Dollars per ton & 13919.9 \\
\hline Tungsten concentrate & Dollars per ton & 8223.6 \\
\hline Mine capacity & Tons per year & 9900000 \\
\hline Dilution ratio & $\%$ & 3 \\
\hline Ore lost ratio & $\%$ & 3 \\
\hline Mining cost & Dollars per ton & 8.96 \\
\hline $\begin{array}{c}\text { Processing } \\
\text { cost(Molybdenum) }\end{array}$ & Dollars per ton & 8.39 \\
\hline $\begin{array}{c}\text { Processing } \\
\text { cost(tungsten) }\end{array}$ & Dollars per ton & 2.49 \\
\hline Recovery(molybdenum & $\%$ & 84.19 \\
\hline ) & $\%$ & 80.65 \\
\hline Recovery(tungsten) & $\%$ & 15 \\
\hline Discount rate & Dollars per year & 7601.49 \\
\hline Fixed costs & t/t & 0.56 \\
\hline Stripping ratio & Dollars per ton & 3.42 \\
\hline Waste ore cost & & \\
\hline
\end{tabular}

Converting tungsten grade into molybdenum grade, the grade-tonnage distribution of two metal deposits is converted into one-dimensional grade-tonnage distribution and cut-off grade optimization of single metal deposit. The equivalent grade-tonnage distribution is shown in Table 2. 
Table 2. The distribution of equivalent grade-tonnage.

\begin{tabular}{ccccc}
\hline $\begin{array}{c}\text { Equivalent } \\
\text { molybden- } \\
\text { um grade } \\
(\%)\end{array}$ & $\begin{array}{c}\text { Ore } \\
\text { quantities } \\
(\mathrm{t})\end{array}$ & $\begin{array}{c}\text { Equivale- } \\
\text { ntaverage } \\
\text { grade } \\
(\%)\end{array}$ & $\begin{array}{c}\text { Molyb- } \\
\text { denum } \\
\text { grade } \\
(\%)\end{array}$ & $\begin{array}{c}\text { Tungs } \\
\text {-ten } \\
\text { grade } \\
(\%)\end{array}$ \\
\hline $0.01-0.02$ & 1606020 & 0.015 & 0.011 & 0.016 \\
\hline $0.02-0.03$ & 6710745 & 0.027 & 0.033 & 0.021 \\
\hline $0.03-0.04$ & 28793760 & 0.035 & 0.035 & 0.015 \\
\hline $0.04-0.05$ & 39301440 & 0.045 & 0.042 & 0.015 \\
\hline $0.05-0.06$ & 37556160 & 0.055 & 0.046 & 0.019 \\
\hline $0.06-0.07$ & 37921440 & 0.065 & 0.049 & 0.025 \\
\hline $0.07-0.08$ & 33568800 & 0.075 & 0.05 & 0.034 \\
\hline $0.08-0.09$ & 36442560 & 0.085 & 0.052 & 0.043 \\
\hline $0.09-0.1$ & 34824960 & 0.095 & 0.055 & 0.05 \\
\hline $0.1-0.11$ & 35478240 & 0.105 & 0.059 & 0.057 \\
\hline $0.11-0.12$ & 33014880 & 0.115 & 0.062 & 0.065 \\
\hline $0.12-0.13$ & 28624320 & 0.125 & 0.067 & 0.072 \\
\hline $0.13-0.14$ & 25619520 & 0.135 & 0.07 & 0.08 \\
\hline $0.14-0.15$ & 22289280 & 0.145 & 0.076 & 0.085 \\
\hline $0.15-0.16$ & 22469280 & 0.155 & 0.081 & 0.093 \\
\hline $0.16-0.17$ & 21408960 & 0.165 & 0.089 & 0.095 \\
\hline $0.17-99$ & 147447360 & 0.247 & 0.134 & 0.145 \\
\hline $0.17 \sim 0.18$ & 18980640 & 0.175 & 0.095 & 0.1 \\
\hline $0.18 \sim 0.19$ & 15805440 & 0.185 & 0.102 & 0.104 \\
\hline $0.19 \sim 0.2$ & 12018240 & 0.195 & 0.107 & 0.108 \\
\hline $0.2 \sim 0.21$ & 9891840 & 0.205 & 0.109 & 0.118 \\
\hline $0.21 \sim 0.22$ & 8620320 & 0.215 & 0.112 & 0.127 \\
\hline $0.22 \sim 0.23$ & 8580000 & 0.225 & 0.117 & 0.134 \\
\hline & & & & \\
\hline
\end{tabular}

Table 3. Scenarios with different equivalent cut-off grade.

\begin{tabular}{ccccccc}
\hline $\begin{array}{c}\text { Cut-off } \\
\text { grade }(\boldsymbol{\%})\end{array}$ & $\begin{array}{c}\text { Ore quantities } \\
\text { (tons) }\end{array}$ & $\begin{array}{c}\text { Average grade } \\
(\boldsymbol{\%})\end{array}$ & $\begin{array}{c}\text { Metal quantities } \\
\text { (tons) }\end{array}$ & Total years & $\begin{array}{c}\text { Recovery } \\
\text { rate (\%) }\end{array}$ & $\begin{array}{c}\text { NPV (million } \\
\text { dollars) }\end{array}$ \\
\hline 0.01 & 593077725 & 0.131 & 776610.2 & 60 & 68.72 & -469.572 \\
\hline 0.02 & 591471705 & 0.131 & 776369.3 & 60 & 68.72 & -465.588 \\
\hline 0.03 & 584760960 & 0.132 & 774557.4 & 59 & 68.75 & -449.713 \\
\hline 0.04 & 555967200 & 0.138 & 764479.6 & 56 & 68.78 & -385.039 \\
\hline 0.05 & 516665760 & 0.145 & 746793.9 & 52 & 70.96 & -237.925 \\
\hline 0.06 & 479109600 & 0.152 & 726138 & 48 & 73.72 & -69.3047 \\
\hline 0.07 & 441188160 & 0.159 & 701489.1 & 45 & 76.00 & 98.15285 \\
\hline 0.08 & 407619360 & 0.166 & 676312.5 & 41 & 76.05 & 196.0799 \\
\hline 0.09 & 371176800 & 0.174 & 645336.3 & 37 & 77.98 & 367.8051 \\
\hline 0.1 & 336351840 & 0.182 & 612252.6 & 34 & 79.50 & 533.3435 \\
\hline 0.11 & 300873600 & 0.191 & 575000.5 & 30 & 79.80 & 671.8768 \\
\hline 0.12 & 267858720 & 0.200 & 537033.4 & 27 & 80.20 & 815.3547 \\
\hline 0.13 & 239234400 & 0.210 & 501253 & 24 & 81.90 & 998.2263 \\
\hline 0.14 & 213614880 & 0.218 & 466666.6 & 22 & 83.20 & 1160.967 \\
\hline 0.15 & 191325600 & 0.227 & 434347.1 & 19 & 83.40 & 1269.186 \\
\hline 0.16 & 168856320 & 0.237 & 399519.8 & 17 & 83.93 & 1389.97 \\
\hline 0.17 & 147447360 & 0.247 & 364661.4 & 15 & 84.33 & 1497.11 \\
\hline 0.18 & 128466720 & 0.258 & 331445.2 & 13 & 84.69 & 1584.56 \\
\hline 0.19 & 112661280 & 0.268 & 302205.2 & 11 & 84.71 & 1635.193 \\
\hline 0.20 & 100643040 & 0.277 & 278769.6 & 10 & 84.75 & 1662.699 \\
\hline 0.21 & 90751200 & 0.285 & 258491.3 & 9 & 85.78 & 1710.686 \\
\hline 0.22 & 82130880 & 0.292 & 239957.6 & 8 & 85.80 & 1705.684 \\
\hline 0.23 & 73550880 & 0.300 & 220652.6 & 7 & 86.20 & 1699.448 \\
\hline
\end{tabular}




\section{Conclusions}

(1) Cut-off grade optimization of multi-metals is proposed based on two stages: mining and processing in this paper. Considering grade-tonnage distribution concentrate market price and recovery rate, the model of multi-metals cut-off grade optimization is constructed using equivalent factor and $N P V$. Objective function is expressed to one variable function by equivalent factor. Multi-metals cut-off grade is converted into a single metal cut-off grade.

(2) A verification example of molybdenum and tungsten is presenting for confirming the cut-off optimization model in this study. The results of optimal cut-off grade and break even cut-off grade are compared in the paper. It provides advice for production of multi-metals mine.

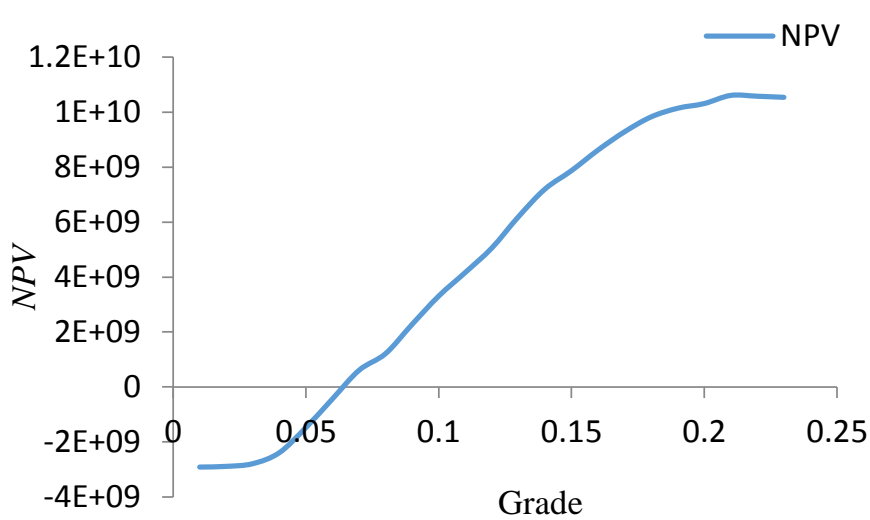

Figure 5. The function curve of cut-off grade and NPV.

Table 4. The optimal scenario with optimal cut-off grade.

\begin{tabular}{cccccccc}
\hline $\begin{array}{c}\text { Equivalent } \\
\text { cut-off } \\
\text { grade (\%) }\end{array}$ & $\begin{array}{c}\text { Qre } \\
\text { quantities(ton } \\
\text { s) }\end{array}$ & $\begin{array}{c}\text { Average } \\
\text { grade (\%) }\end{array}$ & $\begin{array}{c}\text { Molybdenum } \\
\text { grade (\%) }\end{array}$ & $\begin{array}{c}\text { Tungsten } \\
\text { grade (\%) }\end{array}$ & $\begin{array}{c}\text { Metal } \\
\text { quantities( } \\
\text { t) }\end{array}$ & $\begin{array}{c}\text { Total } \\
\text { years }\end{array}$ & $\begin{array}{c}\text { NPV } \\
\text { (million } \\
\text { dollars) }\end{array}$ \\
\hline 0.21 & 90751200 & 0.285 & 0.153 & 0.169 & 258640.9 & 9 & 1710.686 \\
\hline
\end{tabular}

(3) The cut-off grade is calculated with many parameters such as concentrate price, discount rate and costs. Those economic parameters are always variable as market changes. So the cut-off grade is optimal with those parameters and this period. Average value and statistical analysis are usually used to eliminate this influence in this study.

\section{Acknowledgements}

The work was supported by National Natural Science Foundation of China (Grant No. 51404182) and the key discipline of Shaanxi Province (E08001) and Yulin Municipal Science and Technology Project. The authors gratefully acknowledge the cooperation of the Luoyang Luanchuan Molybdenum Industry Group Inc. The authors also thank other participants for their support.

\section{References}

Annels, A.E., 1991. Mineral deposit evaluation-a partial approach. Springer Netherlands, Chapman and Hall, London, 436p. DOI: 10.1007/978-94-011-9714-4

Asad, M.W.A. and E. Topal, 2011. Net present value maximization model for optimum cut-off grade policy of open pit mining operations. The Journal of The Southern African Institute of Mining and Metallurgy, 111(111): 741 - 750.

Cetin, E. and P.A. Down, 2002. The use of genetic algorithms for multiple cut-off grade optimization. Proceedings of the 32nd International Symposium on the Application of Computers and Operations Research in the Mineral Industry, Little, Colorado, 769 - 779.

Dagdelen, K., 1993. An NPV optimization algorithm for open pit mine design. Proceedings of the 24th International Symposium on the Application of
Computers and Operations Research in the Mineral Industry, Montreal, Canada, 257 - 263.

Gu, X.W., Q. Wang, D.Z. Chu and B. Zhang, 2010. Dynamic optimization of cut-off grade in underground metal mining. Journal of Central South University, 17(3): 492 - 497.

Gu, Q.H., J.T. Li and C.W. Lu, 2013. Based on the logistic model of molybdenum, tungsten grade and recovery relationship analysis and prediction. Mining Research and Development, (03):47 - 49(Chinese).

Lane, K.F., 1988. The economic definition of ore, cut-off grade in theory and practice. Mining Journal Books, London.

Li, G.Q., N.L. Hu and X. Song, 2010. Optimization of cutoff grade and its application for poly metallic deposits, Journal of University of Science and Technology Beijing, 32(9): 1107 - 1112. (Chinese)

Li L. and C.W. Lu, 2012. The analysis and prediction of molybdenum concentrate market price in China. Nonferrous Metals Engineering, (03): 21 - 24 (Chinese).

Osanloo, M. and M. Atraei, 2003. Using equivalent grade factors to find the optimum cut-off grades of multiple metal deposits. Minerals Engineering, 16(8): 771 - 776.

Taylor, H.K., 1985. Cut-off grades-some further reflections. Transactions of the institution of Mining and Metallurgy Transaction Section A, (10): 204 - 216.

Whittle, J. and C. Wharton, 1995. Optimizing cut-offs over time. 25th international symposium application of computers and mathematics in the mineral industries, Australia, 261-265.

$\mathrm{Xu}, \mathrm{X} ., 1985$. The marginal grade index system and lane's cut-off grade theory. The Journal of Quantitative\& Technical Economics, (4): 29 - 34. (Chinese)

Xie, Y.L. and Gao Y., 2003. Optimization model of cut-off grade in open pit mine. Jiangxi Nonferrous Metals, (03): 13 - 17. (Chinese) 